are due to the toxin secreted by the bacilli (and the nervous phenomena in all these diseases are often very pronounced) we can readily appreciate that the child who is so prone to the hybrid and indefinite expression of disease, should often be listed for meningitis instead of typhoid fever.

Infectious cerebro-spinal meningitis is often accompanied by a rash similar to that of typhoid fever, and we can readily see how easy it is to make an error in diagnosis in this direction.

This short paper may be condensed into the following conclusions:

1. Typhoid fever occurs more frequently in children than is generally supposed.

2. The fact that ulceration and hemorrhage is much less frequent would explain the absence of pronounced abdominal symptoms.

3. The erratic, undeveloped and hyper-sensitive nerve centers in early child life explain why the toxic secretions of the Eberth bacillus should make cerebral symptoms very pronounced.

4. Given a child of any age with or without intestinal disturbance, with a continued elevated temperature, with or without marked evidence of cerebral disturbance, the possibility of the presence of the Eberth bacillus of typhoid fever should be constantly kept in mind.

\section{FURTHER REPORTS ON THE ABORTION OF TYPHOID FEVER.} Read before the Mississippi Valley Medical Association at Hot Springs,

BY JOHN ELIOT WOODBRIIGE, M.D.

yoUNGSTOWN, OHIO.

When $I$ accepted an invitation to present a paper at your last meeting, selected for my subject the question, Can typhoid fever be aborted, and answered it in the affirmative, antagonizing the teachings of the most learned professors in every medical college in the civilized world, I knew that I should be severely criticized, no matter how conclusive the evidence might be that my views were correct, and I fully realized, to use the words of a distinguished litterateur, that I might expect to stand but sit and sleep on pin points for some years.

Nothing, save the feeling of responsibility for every life sacrificed to typhoid fever, and the positive knowledge of its correctness could have forced from me that affirmative answer; looking back over twelve years experience without a death from typhoid, malarial, or any continued fever, to a preceding series of sixteen years with a death rate of 17 per cent. from typhoid fever alone; and from a time when my brother practitioners were having no better results than I formerly had. On July 17, 1893, I gave in my local society the names and residences of twenty-one cases of typhoid fever out of the large number I had treated. June 25, 1893, I instituted a series of clinical charts and began numbering with 20 , presenting at your last meeting twenty charts, to show the modification of the temperature curve by treatment.

I deem it my duty as a conscientious physician, desiring only the welfare of mankind and the advancement of my profession, to continue the reports of cases falling under my observation. The many grateful letters and kindly words of encouragement I have received from brother physicians, and in some cases from the patients themselves, more than offset the intolerant words and unkindly criticism I have met with from others.

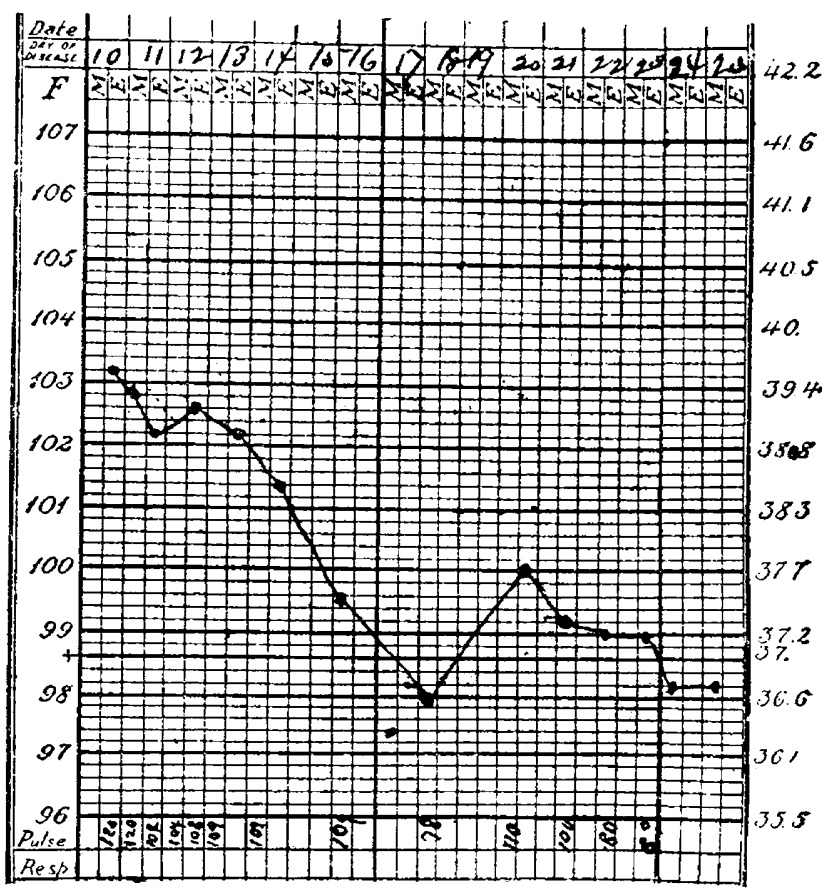

Case 78.-Typhoid fever; name, J. J., age 6 years; residence, Darrow Street; date of admission, July 26,1894 . Result, temperature touched normal on the ninth day.

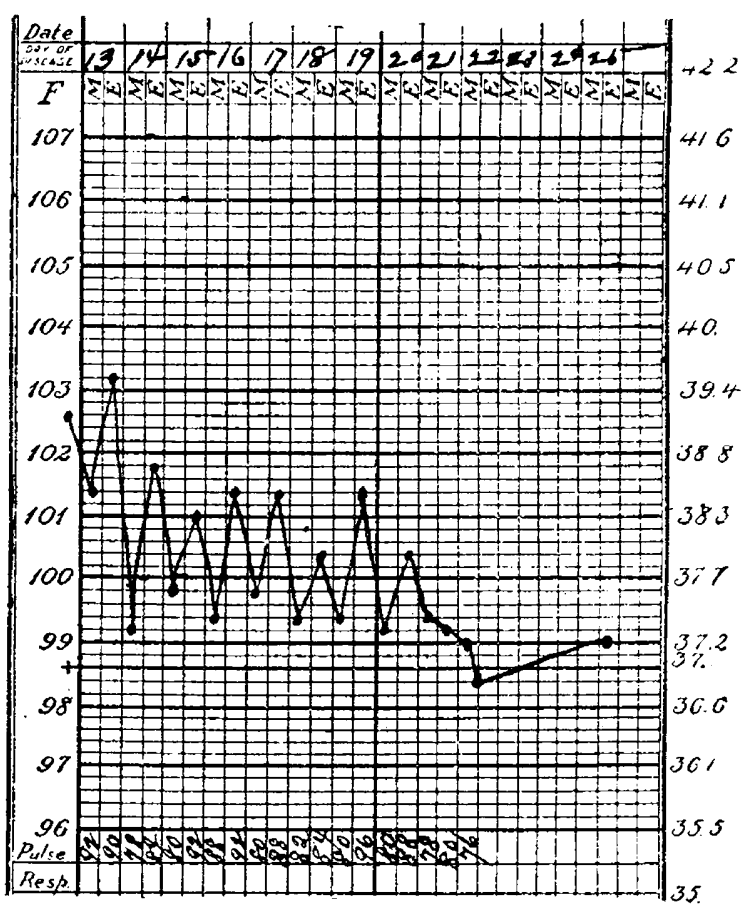

Case 82.-Typhoid fever ; name, Ezra Main ; age 26 ; nativity, American : ccupation, farmer; residence, Trumbull county; date of admission, August 31,1894 . Commenced treatment August 30, one day before removing to the hospital. This patient was diagnosed as typhoid fever and treated a few days by Dr. T. H. Stewart of Church Hill. The symptoms becoming grave he feared to continue without a trained nurse, an expense which the family could not afford; hence he was turued over to me on the twelfth day of his sickness and moved nine miles in an ambulance to the Youngstown City Hosptal. August 31. Bowels very tongue coated, margin red.

I have no feeling of unkindness for those persons, because I know that truth being eternal will prevail, and that my critics of to-day, should we all live, will 
themselves practice the antiseptic abortive treatment in time, and thus vindicate the position which I have been obliged to assume as a logical sequence of the facts I have observed.

I hope, however, that by going annually before some great medical body, reporting the cases in which the fever was aborted during the intervening periods and exhibiting the clinical charts, and premising that I see the cases at a reasonably early stage of the disease with no death to mar the record, that I may ultimately prove heyond the possibility of a doubt that I am not teaching the world to expect or demand more of my profession than it ought. Few can realize the anxiety with which one stands before a representative body like this to say that the greatest thinkers, that all of the great teachers in this most learned of the professions, the highest aim of which is to mitigate human suffering and to save human life, have promulgated an error which in the one disease under consideration cost more than 50,000

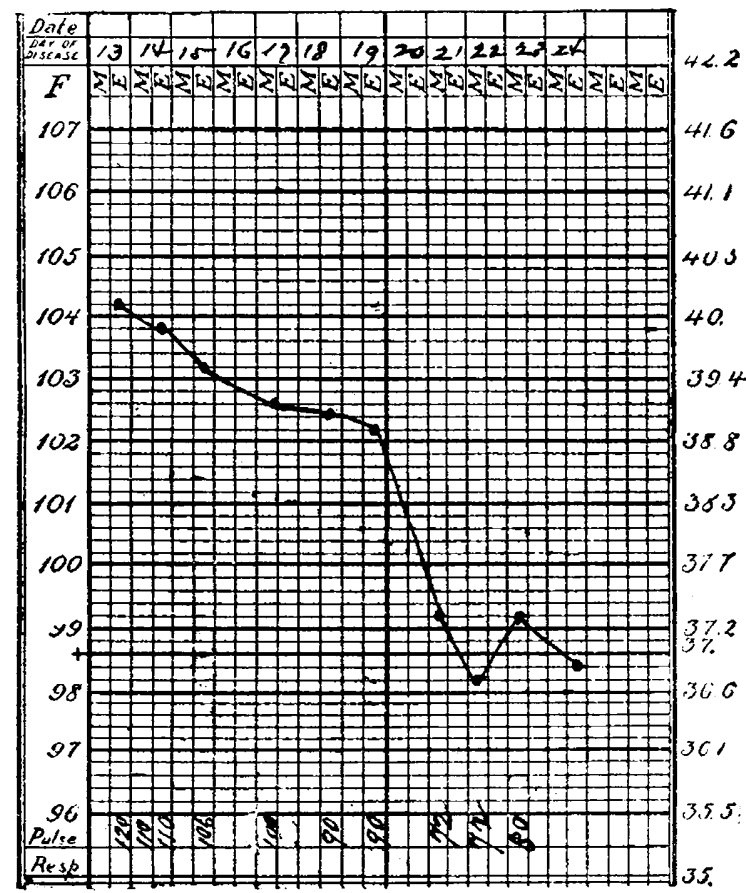

Case 85.-Typhoid fever; name,C. Smith ; age 10 years; residence,Fosterville, Ohio; date of admission, Sept. 13, 1894. This boy lived in a neighborhood where there were several cases of typhoid fever. Was not confined to bed thl of any day, but although presenting well marked symptoms of the disease rode several times on his pony to my office to see me Temperature toluched normal on the tenth day of treatment. September 13. Headache severe for several days past; epistaxis: bowels tender and tympanitic. September 17. Rode his pony to my office.

lives annually and unnumbered years of miserable sickness.

Since our last meeting, I have treated alone or in consultation, fifty-four cases of typhoid fever, without a death and with an average duration of treatment of about twelve days. I had, also, a case of pueumotyphus and two or three cases sent by other phy. sicians at late stages of the disease, one as late as the sixteenth day. I was called during the year to see one case on the thirty-fourth day of sickness when no treatment was needed and another at a somewhat earlier period but when the patient was dying of exhaustion and no treatment was possible. In the Section of General Medicine at the San Francisco meeting of the American Medical Association I reported my cases up to and including No. 75 .
Case 76.-Pneumo-typhus; was in a desperate condition when I was called. She had been sick ten days; was coughing incessantly, raving wildly and having a profuse hemorrhage of the lungs; her pulse was 160 ; temperature 106.4 . She was treated as a case of typhoid fever, with necessary additions in the later stages to meet the lung complication and made a good, though as you will see, not a rapid recovery. She lost all her hair.

Case 78.-John Joyce; was treated until the tenth day of sickness, by the family physician under a first diagnosis of malarial fever. Dr. Cunningham, who had seen some practice in Chicago accompanied me on my first visit having expressed a desire to see some of my work. I asked him to examine the patient and make a diagnosis. He did so, remarking that he should consider it a typical case of typhoid fever. Fearing that his words might frighten the boy's mother who was a stranger to me, I said: "Madame, you need not be alarmed; there is no danger from typhoid fever if it is properly treated." His temperature touched normal as you will see, on the eighth day of treatment.

Case 82.-Was sent to the hospital from the adjoining county of Trumbull, by Dr. T. H. Stewart. He was in the hospital ten days.

One of the best practitioners in Ohio made a diagnosis

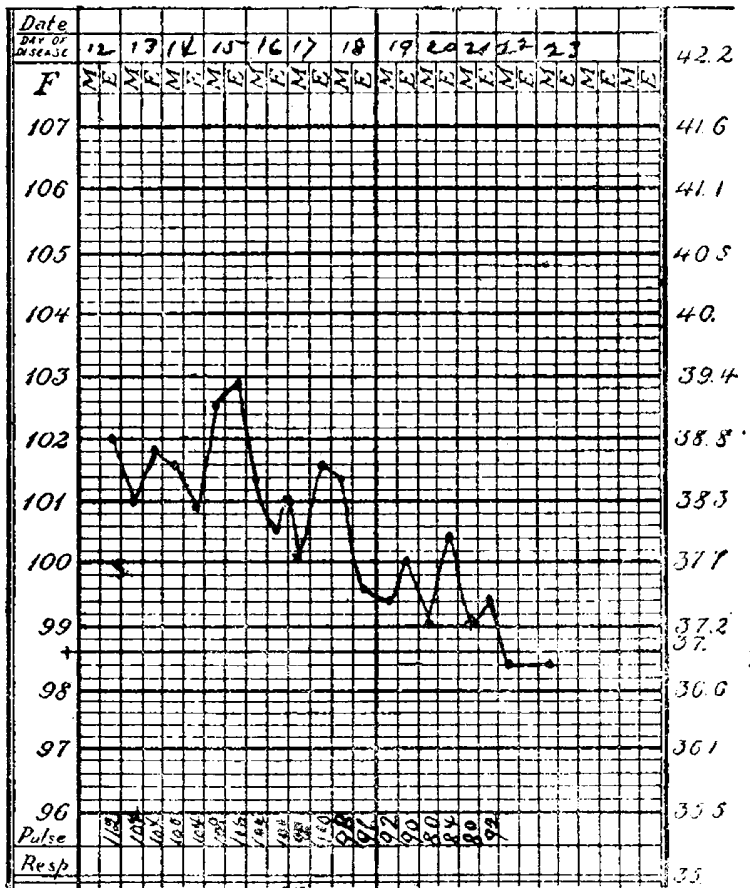

Case 86.-Name, N. H.; age, 17 years; residence, Pine Street ate of admission, Sept. 20,1894 . This patient was under the care of another physician who had prescribed corrosive sublimate and one of the coal tar derivatives; enjoined perfect rest, milk diet; made a prog of sickness. Found a typical case of typhoid fever and gave a prognosis no danger and ten or twelve days sickness. She sat up, having normal tem perature on the tenthe day a phlebitis

of typhoid fever and called me in consultation to Case 83 which made a good recovery.

Case 86 - Was taken sick at the home of her parents, but her physician, recognizing the gravity of her condition had her removed to her sister's in a better and healthier locality, and had her put to bed down stairs, saying that she would be very sick for several weeks. He treated her until the twelfth day of sickness. I was subsequently called to attend this case and being unaware of the Doctor's prognosis, I told the family she would probably be much better in four or five days, and sitting up in ten days, which she did, but had an attack of phlebitis, which greatly prolonged the sickness.

The physician who called me in consultation to Case 83 was himself called in consultation to see Case 86, and after consulting, the two physicians went together to the family (in which there had already been three other cases and one death from intestinal hemorrhage) and told them that Mr. M.'s 
symptoms were all so very bad that they advised that never is any danger of death from typhoid fever when Dr. Woodbridge be sent for in consultation. Upon taken at the stage at which we take this case." Yet consulting with the doctors, I said: "There is no dan- his pulse was 100 , and his temperature was 105.2 ;

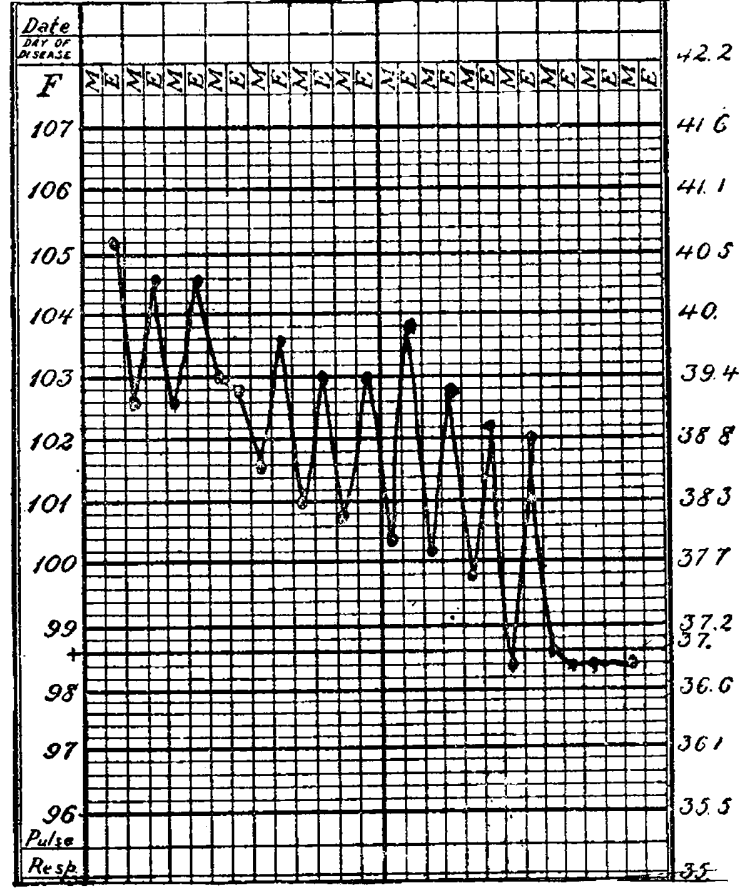

Case 87.-Typhoid fever; name, O. M.; residence, - The fourth case of typhoid fever in the family one having died after an intestinal hemorrhge His nervous symptoms being very severe, his uttendiug physician asked for counsel. A fter consultation with his other physician, he asked to have me called, expressing to the family the opinion that the man would die under any known treatment of typhoid

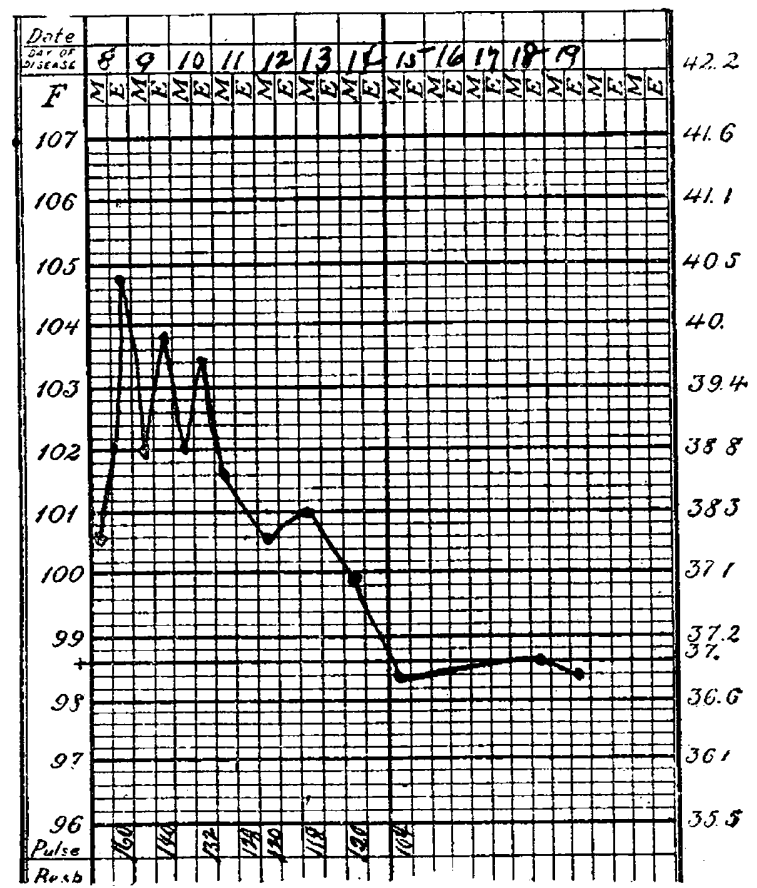

Case s9.-Pneumo-typhus; name, P. G,; age $41 / 2$ years; residence normal on theet; date of admission, Oct.16, the nose bleed, headache severe bowels very tympanitic: slightly delirions. On the twelfth day of treatment rose spots abundant. On the eighteenth laying out of doors but very irritab

ger of a fatal termination. He will have a normal temperature in ten or twelve days;" but added, "there is not only no danger of death in this case, but there

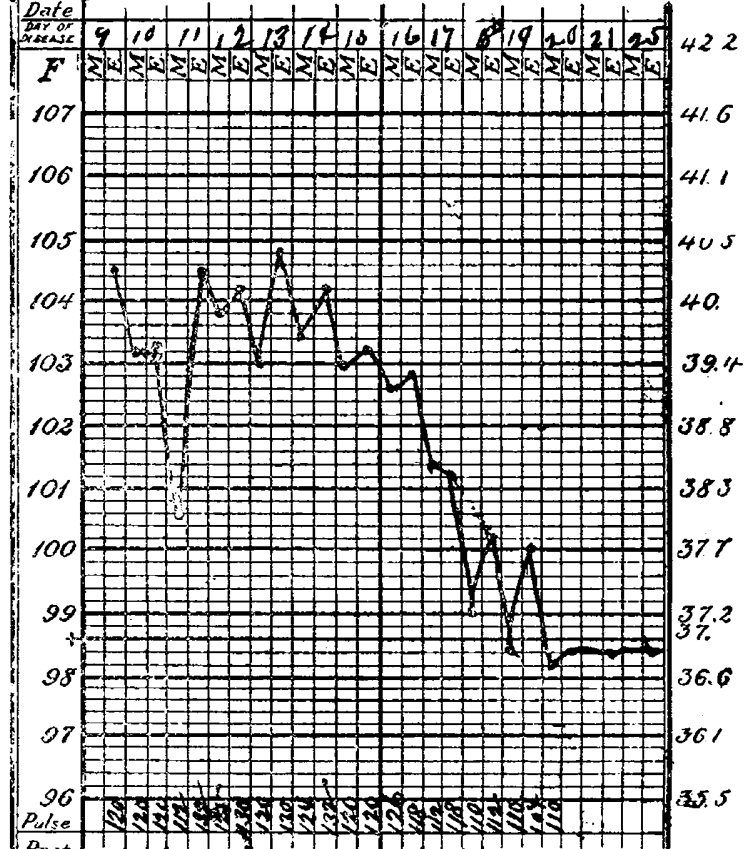

Case 92.-Typhoid fever; Mrs. Yost; age, 24 years; residence, Ilazela treatment. nervor symptoms grave; sleepless. rose spots abundant October 31 Pulse dicrotic. November 1 . Pulse dicrotic.

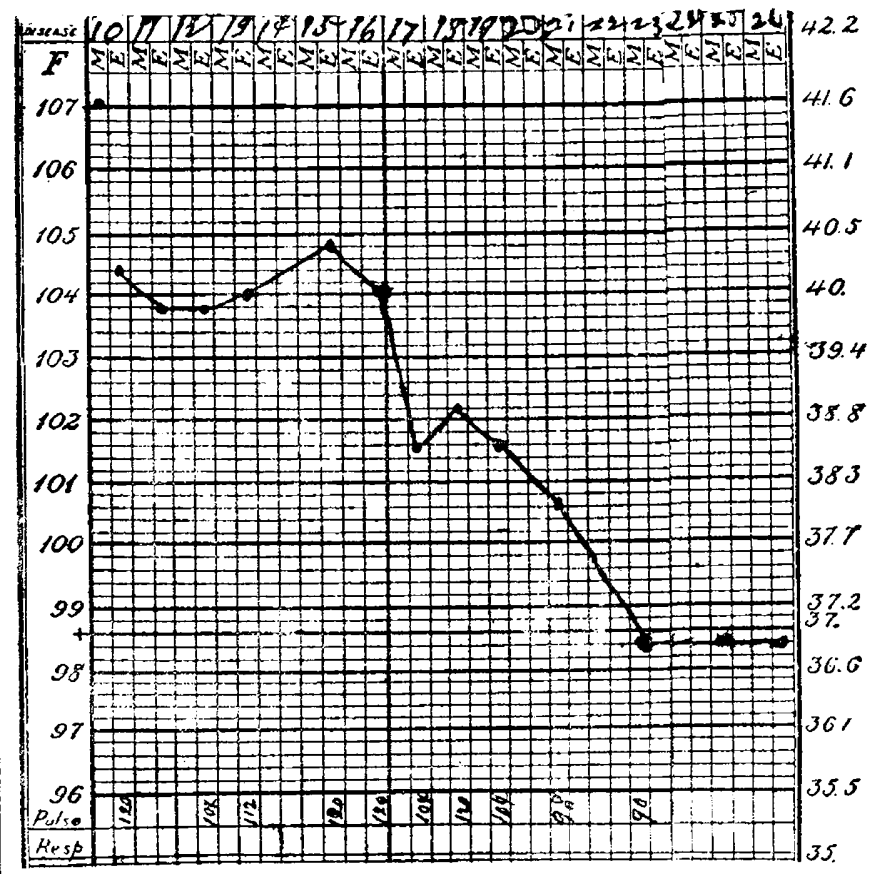

Case 39.-Typhoid fever; name, Mrs. __ ; residence, Thorn Hill, Ohio; date of admission, Oct. 27, 1894 . Sanitary surroundings terrible No fire in house (kitchen separate). No change of bed or body liuen. No attention to the ordinary demands of cleanliness. Husbaud taken from her bedside to jail. Temperature touched normal thirteenth day freatment. When first seel. intense headache; no sleep for three or tober 17. Three hemorrhages of bowels.

his other symptoms were extremely grave, I was not expected to see him again. Prognosis verified by the result. 
Case 91.-Mrs. G., was seen in consultation with her attending physician. Her urine showed large quantities of albumen, and an abundance of both granular and hyaline casts. Her temperature never went above 101 . She had considerable intestinal hemorrhage but made a good recovery.

Case 93.- When called in Case 93, I was told that she had been sick about ten days, but later information led me to believe that she had been sick twelve or thirteen days. Her condition, circumstances and surroundings were horrible; neither any part of her bedding nor her underwear were changed, nor were her face or hands or any part of her body washed during her sickness. There was a cooking stove in a back kitchen somewhere, and no fire anywhere else; it was cold weather with snow much of the time. The room adjoining hers, separated from it only by a loose board partition, was scrubbed once and when I went in the water was standing in puddles. On one of my visits I found the unemptied bed-pan on the bed, and on inquiring found her bowels had moved on the morning of the preceding day. Her husband was taken from her bedside to jail. She had three intestinal hemorrhages in one day. She made, as you see, a rapid recovery, her temperature becoming normal on the twelfth or thirteenth day. She lived so far in the country that I could not visit her every day.

Case 94, 92 and 96.-Dr.J.O.Yost, his wife and sister are in-

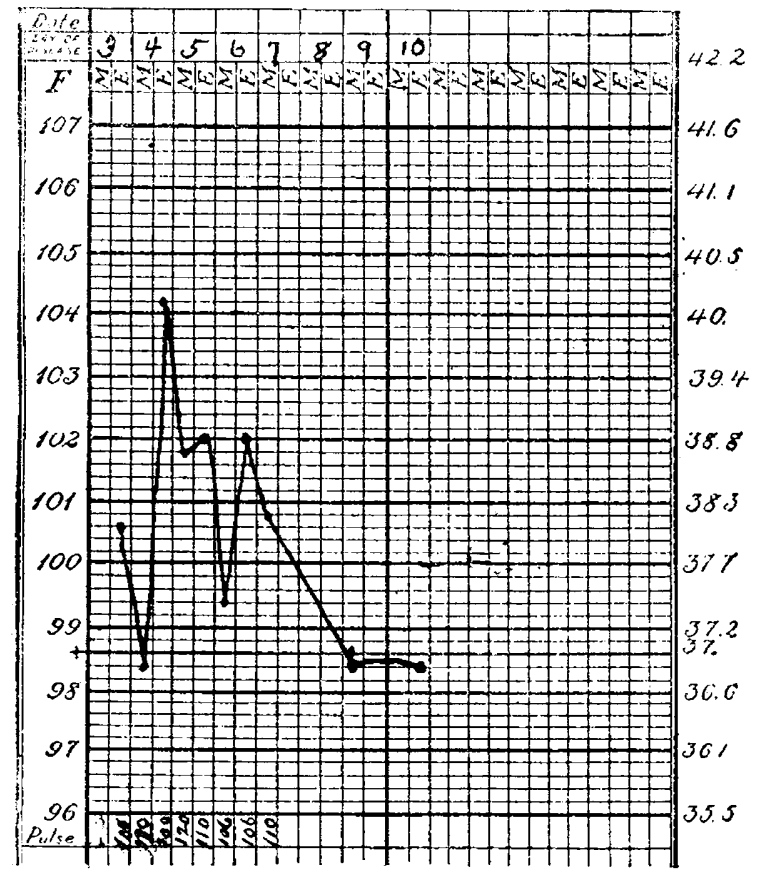

Case 96.-Typhoid fever; name, Kittie Yost; Hazelton, Ohio; date of admission, Nov. 5, 1894. Allowed solid food after the fifth day of treat ment. Diaguosis made by Drs. Bennett and Yost. Nov. 5. Headache produces gurgling.

teresting indeed. Mrs. Yost was under the care of Dr. B., a gentleman of unquestioned ability, who about a year ago passed through a very severe ordeal with typhoid fever, confined to bed six weeks, unable to attend to business an additional three months and even yet not over the effects of the attack. Seeing his patient growing worse, Dr. B. called on me about the tenth day and asked me to see her. I found as he said, a typical case of typhoid fever; the temperature $104 \frac{1}{2}$; the pulse varying between 110 and 134 , which later became dicrotic. The bowels were very tender and tympanitic; marked dullness over the spleen; the margins of the tongue red, the center coated; much gurgling on pressure; a few rose spots which afterward became abundant; nervous and sleepless; very severe headache. A man boarding in a near by house dying, necropsy revealed extensive typhoid lesions and a perforation. The doctors asked if I considered Mrs. Yost in very great danger. I answered, giving my usual prognosis: "Ty" phoid fever is never dangerous if properly treated early." Two days later Dr. B. called my attention to Dr. Y., saying that he himself had typhoid fever. Examining him, I found his symptoms nearly as well marked as were those of Mrs.
Yost, save that his temperature and pulse were not so high or frequent and he had no rose spots.

He said if he were going to be confined to bed he should go home. I said: "Stay and attend to your practice. I assure you that you will be able to at least see patients in your office every day of your sickness," and he was.

Eight days later, Miss Yost was attacked with typhoid fever, not having said anything about being sick as long as she was able to sit up. Her temperature the day before I saw her was 1041/2; her pulse 100, and all her symptoms characteristic. I told the doctor that she would have to to stay in bed three or four days perhaps, but would be well in ten days, and could eat soild food all the time.

This closes the record since our last meeting. Some of the cases diagnosed and numbered as typhoid may possibly have been some other fever, but whatever they were, they all recovered under the treatment of typhoid fever; and this treatment is the least harmful they could possibly have had, there being nothing in it that could possibly be injurious except the little bit of calomel, and of that the dose is exceedingly small, less than one oneshundredth of the dose usually given.

No sane man would dare to go into houses with three or four members of a family sick with typhoid fever, the temperature of some of the patients above 105 degrees and give my invariable prognosis, unless he knew that there was power in medicine to ward off the threatened danger. No man would dare to make the promises I have made for so many years, unless he knew he could fulfill them. Remember, I have invited the closest scrutiny of my cases, and should I have a death from typhoid fever, or fail to abort a case when seen early, it would be emblazoned all over this broad land. But had I twenty years instead of twenty minutes, and could take you back and show you all the evidences that proved to me that typhoid fever can be aborted; could I show you all the typical cases that have yielded to this intestinal antisepsis; show the awful complications that threatened the life; show the white-haired old lady, with the positive proof of a preëxisting Bright's disease, with her repeated intestinal hemorrhages; show you the old man of 73 years, whose young son had succumbed to an intestinal hemorrhage; show the young lady with a year-old ovarian trouble presenting a rounded fuctuating mass through the abdominal walls; show you the wife of Angus McPhee with the blood welling up from her lung, and show you, too, that all of these patients recovered, many of them under the most adverse circumstances, totally disregarding all of the things usually insisted upon as essential to recovery. Many of them with only such nursing as a young child could give. Some giving no attention to restrictions as to diet, and all allowed to use their own pleasure as to exercise and bathing, and yet with no death to mar the record. You would commend my course in making so great a sacrifice and even endangering my professional career in the interest of humanity.

In the abortive treatment of typhoid fever, an early diagnosis is of the first importance. Every case of typhoid fever should be put upon proper treatment the first time seen. There should be absolutely no exception to this rule. If you await the development of pathognomonic symptoms of typhoid fever before beginning treatment, you will not always succeed in aborting the disease. Therefore a diagnosis from any other disease to typhoid fever is wholly unjustifiable, but the reverse is always proper, because the best possible treatment for typhoid fever is also 
a safe initial treatment for any disease for which it could be mistaken.

If you always begin proper treatment when you first see your patient, he will be well often before a positive diagnosis is possible, and you will be deprived of what might otherwise have been a valuable record, but your patient will be the gainer. And after all we are physicians first and investigators afterwards. Hence, when consulted by a patient who could possibly become a victim of typhoid fever, diphtheria, la grippe, pneumonia or any pathologic condition which would be benefited by an intestinal or gystemic antiseptic or eliminant, begin at once the treatment for typhoid fever.

It must not be supposed that because I have begun treatment at almost every stage of typhoid fever and have treated so large a number of cases and have had no death from typhoid fever or any disease that could be mistaken for it for more than twelve years, that such results are always possible. These cases make the proof positive that typhoid fever can be aborted, but it does not follow that it can always be aborted, or even that every life can be saved when it has not been properly treated in its earliest stages.

Next in importance to an early diagnosis, if indeed it should not stand first, is, that your prescriptions be properly compounded of pure and active ingredients. Messrs. Parke \& Davis have for years supplied most of the materials entering into my prescriptions, and latterly they have put up for me, tablets of formulas Nos. 1 and 2, and soft capsules of formula No. 3 in a most satisfactory manner.

Begin the treatment with a tablet of formula No. 1 :

B. Podophyllin ....... . gr. 1-960.

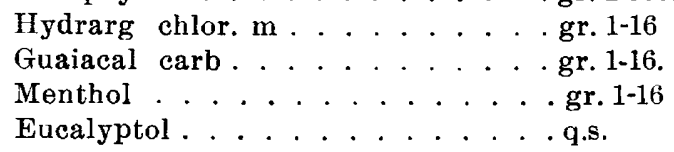

Sig.: Every fifteen minutes.

No laxative effect should be produced during the first twenty-four hours, the object being to secure the antiseptic before the eliminative effect of the remedy. During the second period of twenty-four hours, not less than five or six free evacuations of the bowels should be secured. Then formula No. 2 :

B. Podophyllin ........... 1-960

Hydrarg chlor $m$

Guaiaicol carb . . . . . . . . . gr. 1-4

Menthol . . . . . . . . . . .gr. 1-16

Thymol . . . . . . . . . . . . gr. 1-16

Eucalyptol ...............

B. Guaiacal carb . . . . . . . . gr. iii

Thymol . . . . . . . . gr. i

Menthol ........... gr. ss

Eucalyptol .......... . m j

One or more tablets every hour or two should be given with No. 1 as frequently and in as large doses as possible without produeing too much laxative effect, and as long as necessary if no symptoms of ptyalin (a wholly unnecessary complication), appear, in which event they must be discontinued promptly. for a day or two, and if necessary chlorate of soda or potash given, returning as soon as possible to formulas Nos 1 and 2. The object is to give these remedies as freely as possible at first, and then so gradually reduce the size and frequency of the doses as to allow the movements of the bowels to become less and less frequent, until, as the temperature approaches normal, the movements shall be reduced to one or two each day. About the fourth or fifth day of treatment begin No. 3 every three hours.

Every dose of medicine should be washed down with large draughts of distilled or sterilized water, or according to indications with some good laxative or diuretic mineral water.

This treatment begun early and intelligently carried out will, if the remedies are pure, active and properly prepared, abort typhoid fever and a death from the disease will be unknown.

ORIGINAL INVESTIGATIONS ON THE NATURAL HISTORY, (SYMPTOMS AND PATHOLOGY) OF YELLOW

FEVER. 1854-1894.

BY JOSEPH JONES, M.D., LL.D. NEW ORLEANS, LA.

(Continued from page 948.)

Chapter III.

CHANGES OF THE TEMPERATURE, PULSE AND RESPIRATION IN YELIOW FEVER.

Owing perhaps chiefly to the sudden origin, rapid progress, and singularly fatal nature of yellowfever, as well as the infrequency of the use of the thermometer in the investigation of the disease, but few facts of value relating to the definite degrees of temperature in the different stages of the disease can be found in the writings of various observers. Almost all observers, however, as Benjamin Rush, ${ }^{15} \mathrm{~J}$. Deveze, ${ }^{16 .}$ Wm. Currie, ${ }^{17} \mathrm{C}$. Caldwell, ${ }^{18}$ Samuel Jackson, ${ }^{19}$ P. Chas. A. Louis, ${ }^{20} W$. Arnold, ${ }^{21}$ R. Jackson, ${ }^{22}$ Lionel Chalmers, ${ }^{23}$ John Lining, ${ }^{24}$ A. M. F. Savarésy, ${ }^{25}$ William T. Wragg, Daniel Blair, ${ }^{26}$ John Davy, ${ }^{27}$ Schmidtlein, ${ }^{28}$ and many others, concur in the statement that in the early stage of reaction or febrile excitement the temperature is elevated to a greater or less degree, in different cases, above the standard of health; and still further, that this elevation of temperature is not permanent, but at the end of from two to five days, in most cases, is succeeded by a decided fall; and although the symptoms may be of the gravest character and the patient in extremis, neither the elevation of the temperature nor the frequency of the pulse. give any true indication of the danger.

Dr. John Lining, of Charlestown, S. C., appears to have been the first physician who recorded definite observations on the variations of the temperature in yellow fever. In his description of the American yellow fever, contained in a letter addressed to Dr. Robert Whyte, Professor of Medicine in the University of

15 Medical Inquiries and Observations (4 vols. octavo), Philadelphia, 1809.

ic Recherches et Observations sur la Maladie Epidemique qui à régne à Philadelphia, en 1793; Dissertation sur le Fievre Jaune, Traité de la Fievre Jaune, etc

17 Treatise on the Synochus Icterodes, etc., 1794

19 An Account of the Yellow or Malignant Fever which appeared in 19 An Account of the Yellow or Malignant Fever which ap

city of Philadelphia in the Summer and Autumn of 1820. 20 Anatomic, Pathologic, and Therapeutic Rese

ever of Gibralter, 1828; translation, Boston, 1839 . ever) etc., London, 1840 .

22 Treatise on the Fevers of Jamaica. Lond on, 1791. 1768. Whytt.

cription of the American Yellow Fever, in a letter to Dr.

25 De la Fievre Jaune, etc. Naples, 1809

26 Some Account of the last Yellow Fever Epidemic of British Guiana. Third edition, London, 1852 .

27 Notes to Blair's Account of the last Yellow Fever Epidemic of British Guiana.

28 On the Temperature in Diseases, by Dr. C. A. Wunderlich. (Sydenham Society, page 405 .) 